\title{
TOURIST QUALITY OF SPAIN BEACHES UNDER THE PERSPECTIVE OF SUSTAINABILITY
}

\author{
Mercedes Raquel García Revilla1, Olga Martínez Moure1, Dorin Paul Bac ${ }^{2 *}$ \\ 1 Universidad a Distancia de Madrid, UDIMA, Madrid, Spain \\ 2 Department of Economics and Business, Faculty of Economic Sciences, University of \\ Oradea, Oradea, Romania \\ mercedesraquel.garcia@udima.es \\ olga.martinez@udima.es \\ bacdorin@gmail.com
}

\begin{abstract}
An exploration of the Autonomous Communities of Spain with the highest number of beaches with $Q$ of quality is studied in this work. The purpose of this paper is to analyzed the Autonomous Community with the more $Q$ of Quality and study the differences between the tourism expenditure in this region. The $Q$ of quality is a certificate granted by the Institute for Spanish Tourism Quality that guarantees high quality in certain sectors. This study finds that Andalusia is the main autonomous community with the highest number of beaches with quality $Q$. In addition to this, a comparison between the average expenditure of residents in Spain and foreigners who take leisure trips is analyzed in this study. However, when comparing the average expenses of people who do tourism in Andalusia to the average cost throughout the entirety of Spain during their vacations and holidays, it was determined that they are not significantly different. Even so, a significant difference between the average expenditure of residents and tourists in Spain is determined. In future research, this study will be extended to the other Autonomous Communities of Spain to find differences among them.
\end{abstract}

Keywords: sun and beach tourism, quality $Q$, sustainability.

JEL classification: Z32

\section{Introduction}

Sustainability in general and it's influences on tourism has been the main focus of numerous papers during the last few years (Sverdrup and Svensson, 2002; Dresner, 2008; Badulescu and Badulescu, 2012; Badulescu D. et al, 2015). There are numerous types of tourism destinations: mountains, seaside, cultural cities or music festivals, and they all have different levels of sustainability. In the case of seaside tourism, researchers have focused on different topics: residents' atitude (Lundebrg, 2017), urban logistics in seaside resorts (Hacia, 2016) and social issues generated by tourists (Agarwall et.al. 2018).

Because Spain has been one of the most important tourism destinations (UNWTO 2019), sustainability has been important for both authorities and researchers. Considering the complexity of Spanish tourism resources, some authors have focused on World heritage sites (Dans and Gonzalez 2019), regional development (Carrillo and Jorge, 2017) and of course coastal destinations (Blancas et. al. 2010).

One of the most important tourism destinations in Spain is the region of Andalusia. It is located in the southern part of Spain, and it has a total land surface of $87.268 \mathrm{~km}^{2}$ and a

\footnotetext{
* Corresponding author: Bac Dorin
} 
total population of 8,41 million (Eurostat 2019). The region attracts tourists for several reasons: sea and sun, health, culture, conferences and congresses etc.

From a regional perspective, tourism is an important factor in the Andalusian economy because it generates employment and produces a multiplier effect that influences other activities that make up the regional pproduction system (Andalusía Board, 2018). In more detail, tourism is like a driving force for the regional and local economic growth of a country, especially in those regions where it forms a relevant activity collated with the other sectors (OMT, 2015).

The growing demand in this field requires greater orientation towards more sustainable and efficient models that offer quality and innovation in their services (Andalusian Board / Junta de Andalucía, 2018).

Notably, tourism is subjective to territory because a natural territory such as beaches can be attractive for tourists. In addition, the displacement to a particular place is conditioned depending on the territory, as well as to the type of tender that is offered due to the territory and the ability to adjust and model tourism through policies (OMT, 2015). In this sense, the term "tourist product" can be encompassed by the combination of aspects, such as characteristics of the places visited, means of transport, types of accommodation, specific activities offered at the destination, among others. This is placed around a certain center of interest (e.g., excursions, tours, sports). In this way, gastronomic tourism, ecotourism, city tourism, rural tourism, sun and beach tourism, winter tourism, health tourism, among others can be tourism products (RIET, 2008).

This paper is dedicated to presenting a quantitative exploratory study on the sun and beach tourism product in Spain. Specifically, the data regarding the $Q$ of quality on the beaches of Spain are examined, and the average tourism expenditure by residents in Spain and foreigners are differentiated.

The structure of this work is organized as follows: section 2 is dedicated to representing the state of art necessary for the development of this work. The $Q$ of quality, descriptive statistics, normality test and test for two samples are the concepts which are presented. Section 3 presents the results obtained with each of the methods explained in the previous section. Finally, in section 4, the results obtained and their conclusions are discussed.

\section{Research methodology}

\subsection{Q of Quality}

Any tourist company whose commercial sector has a Reference Standard can request the Spanish Tourism Quality Q mark (Calidad Turística Española, 2017). This Q of Quality consists of a quality mark awarded by the Spanish Tourism Quality Institute (ICTE).

The ICTE is a Spanish, private, independent, non-profit organization. In detail, it consists of a Quality Systems Certification Entity that has been created especially for tourism companies. ICTE is made up of the most significant national tourism entities in Spain, for example, the SET, the CCAA and the FEMP.

\subsection{Descriptive statistics}

Descriptive statistics is a branch of mathematics that collects, presents and characterizes a set of data. Thus, the characteristics of a data set are adequately described with descriptive statistics.

The Box Plot or Mustache Diagrams are a convenient way to visualize the distribution of data through their quartiles. Sometimes outliers are plotted as individual points aligned with the whiskers (Sidney y Castellan, 1988). 


\subsection{Shapiro-Wilk Normality Test}

Goodness of fit tests are dedicated to determine if the data of a population fits a given distribution. One of these goodness-of-fit tests is the Shapiro-Wilk normality test, which contrasts for a certain level of confidence the null hypothesis, that the data comes from a population with normal distribution, especially for a small sample of data. The following hypotheses are what this test contrasts:

Null hypothesis $H_{0}$ : the data is normally distributed.

Alternative hypothesis $H_{1}$ : the data is not normally distributed. The contrast orders the sample from least to greatest and then calculates a contrast statistic:

$$
W=\frac{1}{n s^{2}}\left(\sum_{i=1}^{h} a_{i n}\left(x_{(n-i+1)}-x_{(i)}\right)\right)^{2}
$$

Where let $s^{2}$ be the sample variance,

$$
h=\left\{\begin{array}{c}
\frac{n}{2}, \text { if } n \text { is pair } \\
\frac{n-1}{2}, \text { if } n \text { is odd }
\end{array}\right.
$$

and $a_{\text {in }}$ can be found in the statistical tables.

Then, if the value of the statistic is lower than a pre-established level of significance, the null hypothesis is rejected and, therefore, the data is not normally distributed.

\subsection{Tests for two samples}

Usually, using the Student's t-test you can compare two populations and determine if there are significant differences between them. The procedure can consist of two classes depending on how both samples are constructed:

1. Paired samples: where each observation in a group has an observation associated with the second group.

2. Independent samples: where the individuals of a treatment group have been extracted independently of those from the other group.

When the study population has a normal distribution, this test for two samples is adequate. Otherwise, the Mann-Whitney or Mann-Whitney-Wilcoxon $U$ test is adequate for independent samples that are not normally distributed.

The Mann-Whitney $U$ test is used to check the heterogeneity of two ordinal samples.

This test calculates a $U$ statistic, which establishes for each of the values of the two samples its range to construct (Sidney y Castellan, 1988).

$$
U_{1}=n_{1} n_{2}+\frac{n_{1}\left(n_{1}+1\right)}{2}-R_{1} \quad U_{2}=n_{1} n_{2}+\frac{n_{2}\left(n_{2}+1\right)}{2}-R_{2}
$$

Where let $n_{1}$ y $n_{2}$ be the simple size, let $R_{1}$ y $R_{2}$ be the sum of the ranges of the sample

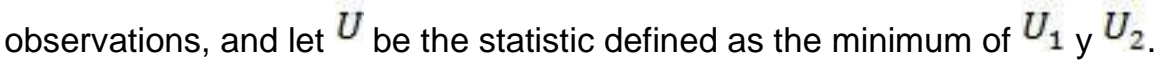

The statistic $U$ is given by the following expression: $\quad z=\frac{\left(U-m_{U}\right)}{\sigma_{U}}$ 
where $m_{U}=\frac{n_{1} n_{2}}{2}$ y $\sigma_{U}=\sqrt{\frac{n_{1} n_{2}\left(n_{1}+n_{2}+1\right)}{12}}$.

\section{Results and findings}

\section{1. $Q$ of Quality}

Spain is made up of 17 autonomous communities, out of which only 15 have access to the sea, and 11 of those have quality $Q$ beaches. The number of certified beaches that obtained the Q of Tourism Quality in Spain in 2017 by autonomous community can be seen as follows bewllow. Notice that the Autonomous Community with the highest number of beaches with quality $Q$ is Andalusia (Figure 1). It can be noted that Andalusia almost doubles the number of beaches with $Q$ of quality than the Valencian community, which occupies the second position. The communities that have less beaches with quality $Q$ are the Basque country and the Canary Islands.

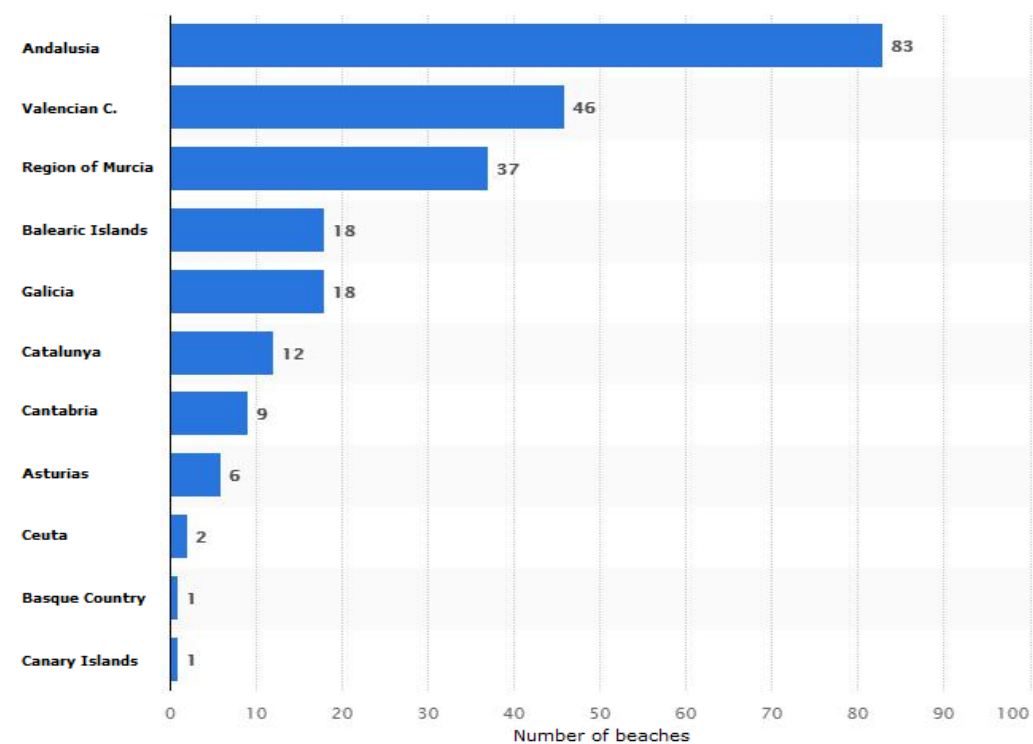

Figure 1. Number of beaches certified with the Q of Tourism Quality in Spain in 2017 by autonomous community.

Source: Statistics National Institute 2017

\subsection{Descriptive analysis}

This section describes the data to be analyzed, which is composed of the three study populations described below:

Andalusia (1): corresponds to the average expenses incurred by residents in the Community Autonomous of Andalusia.

Spain (2): corresponds to the average expenses incurred by residents in Spain.

Foreigners (3): corresponds to the average expenses incurred by residents in other countries. Each of the three study populations is described below: 
Table 1: Statistics of the average expenditure (in euros) by residents in Andalusia, Spain and foreigners.

\begin{tabular}{|l|c|c|c|c|c|c|}
\hline & N & Range & Min & Max & Mean & Std. dev \\
\hline Andalusia & 32 & 171,30 & 137,82 & 309,12 & 201,9228 & 46,94205 \\
\hline Spain & 32 & 153,44 & 136,17 & 289,61 & 187,3778 & 44,24357 \\
\hline Foreigners & 32 & 528,09 & 491,02 & 1019,11 & 775,3831 & 136,08897 \\
\hline N valid (list) & 32 & & & & & \\
\hline
\end{tabular}

Source: made by the authors

Figures 2, 3 and 4 show the average expenses of residents in Andalusia, residents in Spain and foreign residents, respectively. In these Figures, it is observed that the average expenditure has a seasonal behavior, which increases during the holidays and decreases outside of holiday periods.

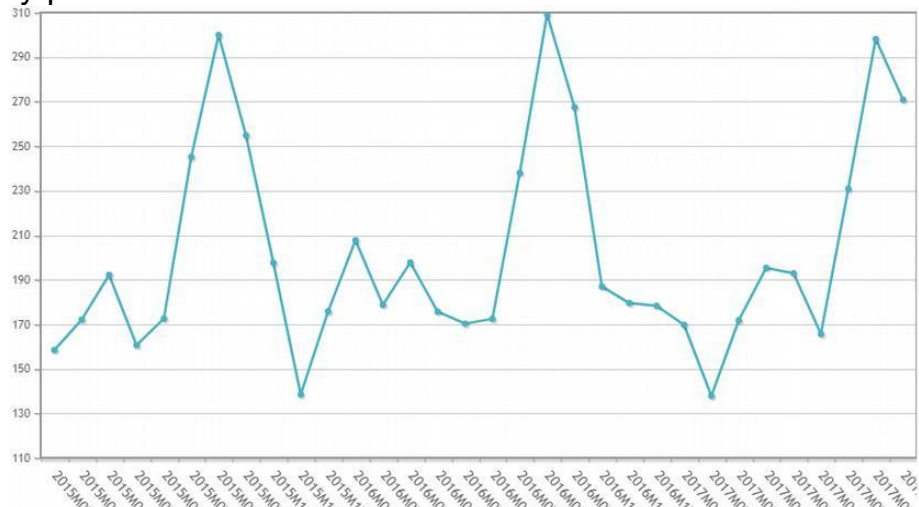

Figure 2: Average expenditure by residents in Andalusia

Source: Statistics National Institute 2017

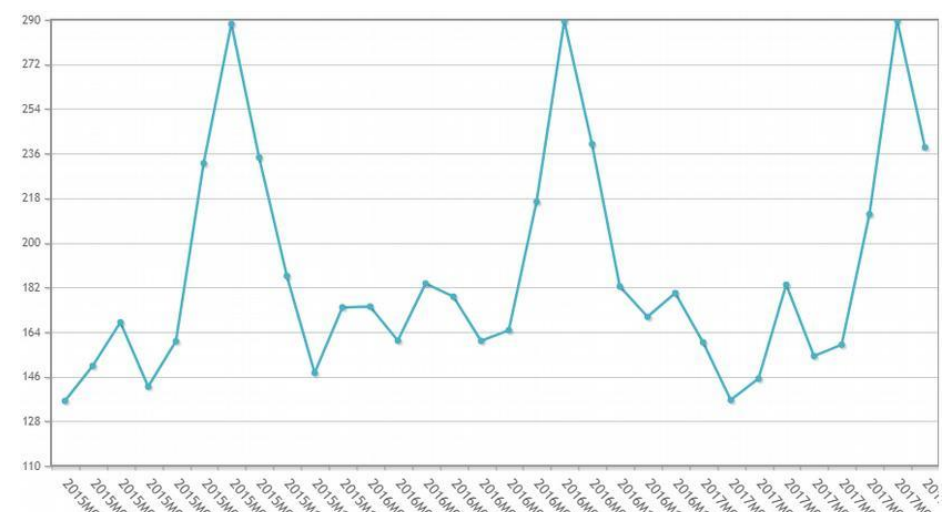

Figure 3: Average expenditure by residents in Spain

Source: Statistics National Institute 2017 


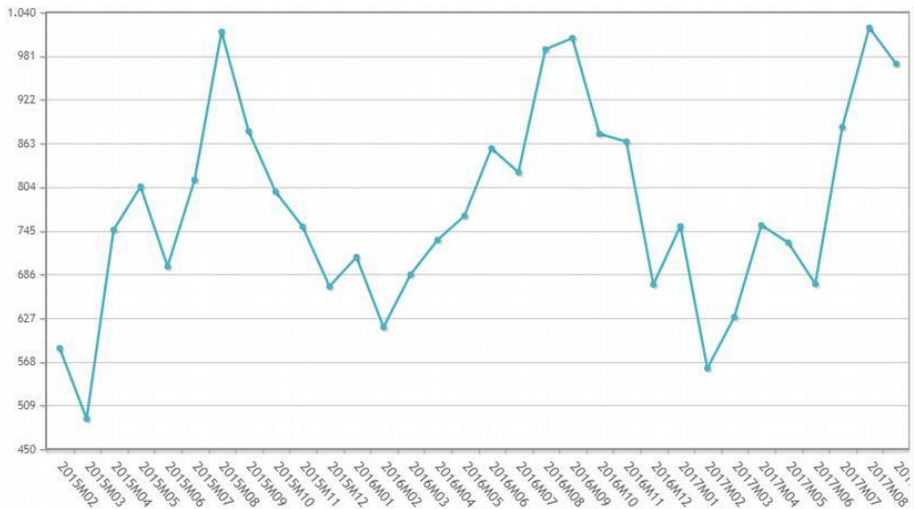

Figure 4: Average expenditure by foreign residents

Source: Statistics National Institute 2017

\subsubsection{Box and mustache diagram}

In the figure below, the difference between the average expenditure of these three populations in question is observed. It is noted that residents in foreign countries make a higher average of the expenditure as compared to residents in Spain. Likewise, the shape of the boxes for the two populations of Spain, suggests that they are not normally distributed.

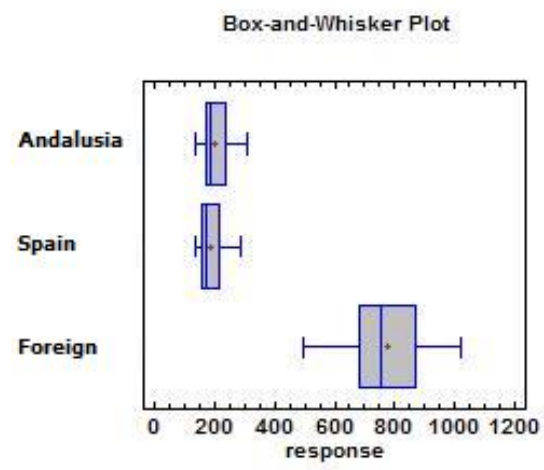

Figure 5: Diagram of average expenditure boxes by residents in Andalusia, Spain and foreign countries.

Source: own elaboration

\subsection{Normality test}

The Shapiro-Wilks test raises the null hypothesis that a sample comes from a normal distribution. We choose a level of significance, for example 0.05 , and we have an alternative hypothesis that maintains that the distribution is not normal. We have:

$\mathrm{H}_{0}$ : The distribution is normal

$\mathrm{H}_{1}$ : The distribution is not normal

\subsubsection{The case of Spain}

Table 2: Normality test for Spanish residents.

\begin{tabular}{|c|c|c|}
\hline Test & Statistic & p-value \\
\hline Shapiro-Wilk & 0,850515 & 0,000280514 \\
\hline
\end{tabular}

Source: own elaboration 


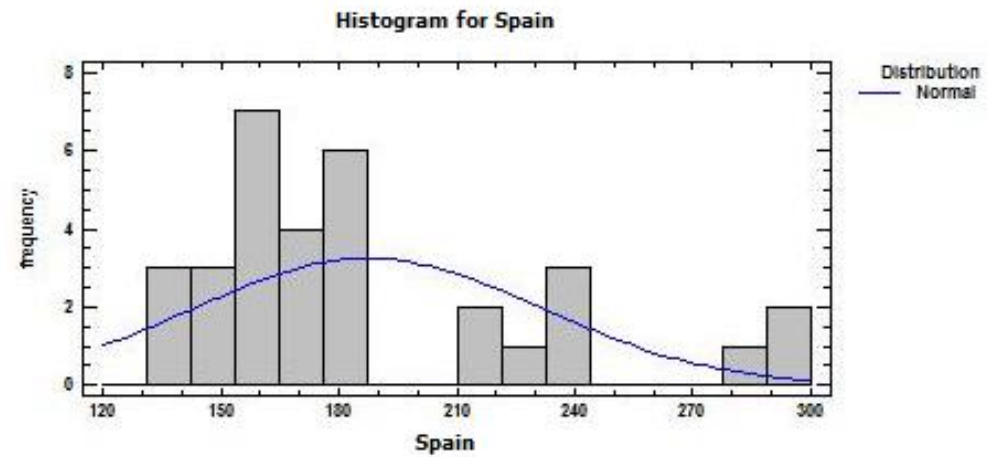

Figure 6: Histogram of average expenditure by residents in Spain Source: own elaboration

The data of this population is not normally distributed as is shown in Table 2 where the $p$ value is lower than 0.05 and it can be seen in the histogram in Figure 6.

\subsubsection{The case of Andalusia}

It is concluded that the data of this population does not have a normal distribution as seen in Table 3 and Figure 7 because the p-value is greater than 0.05 .

Table 3: Normality test for Andalusian residents.

Source: own elaboration

\begin{tabular}{|c|c|c|}
\hline Test & Statistic & p-value \\
\hline Shapiro-Wilk & 0,869859 & 0,000918306 \\
\hline
\end{tabular}

Histogram for Andalusia

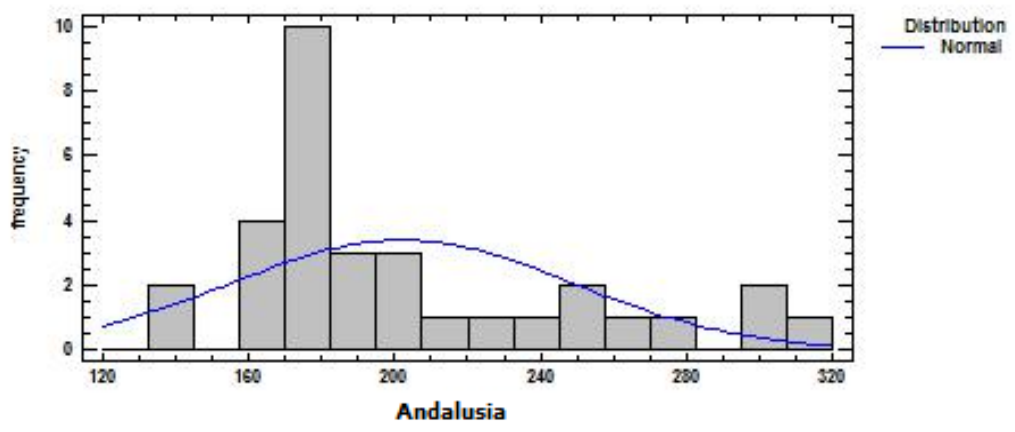

Figure 7: Histogram of average expenditure by residents in Andalusia.

Source: own elaboration

\subsubsection{The case of foreigners}

There is no evidence to reject the null hypothesis that indicates that the data of this population has a normal distribution as seen in Table 4 and Figure 8 because p-value is greater than 0.05 .

Table 4: Normality test for foreign tourists.

Source: own elaboration

\begin{tabular}{|c|c|c|}
\hline Test & Statistic & p-value \\
\hline Shapiro-Wilk & 0,969563 & 0,547912 \\
\hline
\end{tabular}




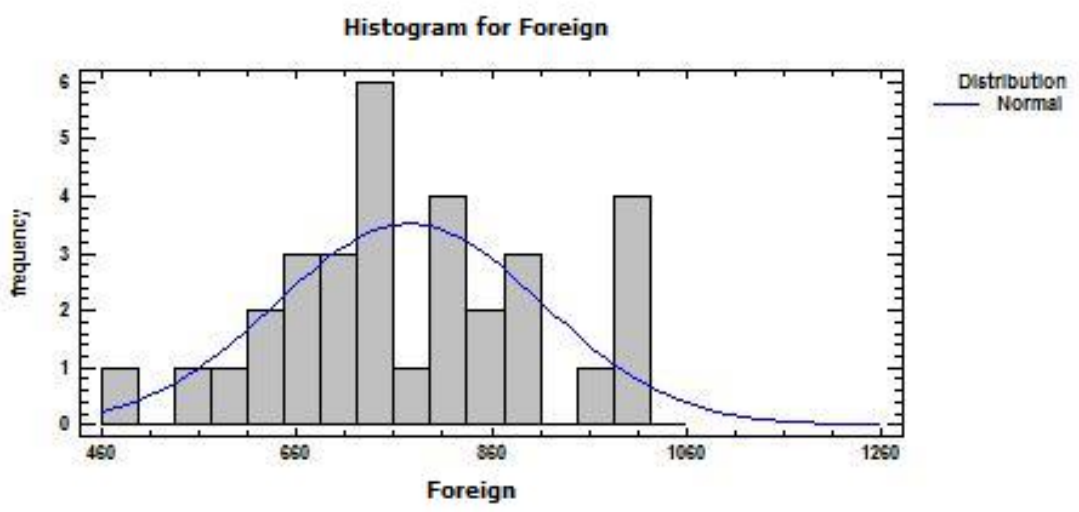

Figure 8: Histogram of average expenditure by foreign tourists.

Source: own elaboration

\subsection{Test for two samples}

It is important to determine if there are differences between the average expenditure of residents in Spain with foreigners and the average expenditure of residents in Andalusia with residents in Spain. Thus, the differences between the two groups, the communities that integrate cities with this distinction and those that do not, by comparing populations for independent samples are studied. Therefore, in the first place, it is necessary to study whether the variable "average expenditure" for the three populations is normally distributed by means of a visualization of the corresponding histogram and the Shapiro-Wilk test.

To do this, we proceed to study the differences between these groups through the nonparametric statistical test of Mann-Whitney U.

The results obtained with the Mann-Whitney $U$ test are shown in the following subsections

\subsubsection{Spain - Foreigners}

The tables below confirm that the observed difference between these two types of communities is statistically significant because the $p$-value is lower than 0.05 .

Table 5: Mann-Whitney U test result among residents and other foreign countries.

\begin{tabular}{|l|l|l|l|l|}
\hline \multirow{2}{*}{ Tourism } & \multicolumn{4}{|c|}{ Ranks } \\
\cline { 2 - 5 } & id & $\mathbf{N}$ & Average Range & Sum of Ranges \\
\cline { 2 - 5 } & 2,00 & 32 & 16,50 & 528,00 \\
\cline { 2 - 5 } & 3,00 & 32 & 48,50 & 1552,00 \\
\hline
\end{tabular}

Source: own elaboration

Table 6: Contrast statistics (Grouping variable: id).

Source: own elaboration

\begin{tabular}{|l|l|}
\hline & Tourism \\
\hline U of Mann-Whitney & 0,000 \\
\hline W of Wilcoxon & 528,000 \\
\hline Z & $-6,875$ \\
\hline p-value & 0,000 \\
\hline
\end{tabular}




\subsubsection{Andalusia - Spain}

In Tables 7-8 can be noticed that the $p$-value cannot be rejected because it is greater than 0,05 so, there is no difference observed between these two types of statistically significant communities.

Table 7: Mann-Whitney U test result among residents in Andalusia and throughout Spain.

\begin{tabular}{|l|l|l|l|l|}
\hline \multirow{2}{*}{ Tourism } & id & $\mathbf{N}$ & Average Range & Sum of Ranges \\
\cline { 2 - 5 } & 1,00 & 32 & 36,41 & 1165,00 \\
\cline { 2 - 5 } & 2,00 & 32 & 28,59 & 915,00 \\
\cline { 2 - 5 } & Total & 64 & & \\
\hline
\end{tabular}

Source: own elaboration

Table 8: Contrast statistics (Grouping variable: id).

Source: own elaboration

\begin{tabular}{|l|l|}
\hline & Tourism \\
\hline U of Mann-Whitney & 387,000 \\
\hline W of Wilcoxon & 915,000 \\
\hline Z & $-1,678$ \\
\hline p-value & 0,093 \\
\hline
\end{tabular}

\subsubsection{Andalusia - Foreigners}

The tables below confirm that the difference observed between these two types of communities is statistically significant, with a p-value lower than 0.05 .

Table 9: Mann-Whitney $U$ test result among residents in Andalusia and other foreign countries.

\begin{tabular}{|l|l|l|l|l|}
\hline \multirow{2}{*}{ Tourism } & \multicolumn{4}{|c|}{ Ranks } \\
\cline { 2 - 5 } & id & $\mathbf{N}$ & Average Range & Sum of Ranges \\
\cline { 2 - 5 } & 1,00 & 32 & 16,50 & 528,00 \\
\cline { 2 - 5 } & 3,00 & 32 & 48,50 & 1552,00 \\
\cline { 2 - 5 } & Total & 64 & & \\
\hline
\end{tabular}

Source: own elaboration

Table 10: Contrast statistics (Grouping variable: id).

Source: made by the authors

\begin{tabular}{|l|l|}
\hline & Tourism \\
\hline U of Mann-Whitney & 0,000 \\
\hline W of Wilcoxon & 528,000 \\
\hline Z & $-6,875$ \\
\hline p-value & 0,000 \\
\hline
\end{tabular}

Data processing was done with IBM SPSS Statistics 20 and Statgraphics Centurion XVI.I, with maximum levels of significance for the contrast of statistical tests of $p=0.05$.

\section{Conclusions}

In this study, Andalusian tourism descriptive statistics have been analyzed in order to know more of this Spain Community which is very touristic all year round. In the first place, it has been found that Andalusia is the Autonomous Community with the highest number of 
beaches with $Q$ of Quality. In addition, a higher average expenditure during holidays by residents of this autonomous community is obtained. However, it was found that there are no significant differences in the average expenditure of the residents of Andalusia with respect to the average expenditure made by residents in Spain during their days of tourism. Although there is a difference between the average expenditure of residents in Andalusia and throughout Spain and that of foreigners who do tourism in the country. In this way, it can be concluded that besides being the Community of Spain with the most beaches with $Q$ of Quality, it is a Community that has significant benefits during the holidays both from residents and also from foreigners. This study can be extended to other Communities of Spain in order to find significant differences between them.

\section{References}

Agarwall, S., Jakes, S., Essex, S., Page, S., Mowforth M. (2018) Disadvantage in English seaside resorts: A typology of deprived neighbourhoods. Tourism Management, 69, pp. 440 -459 .

Andalusian Board (2018) Directorio de establecimientos y espacios certificados, available online at: http://www.juntadeandalucia.es/turismoydeporte/publicaciones/143595753.pdf Badulescu, A, Badulescu, D. (2012). Entrepreneurship and Local Resources, in Leslie, D. (Ed.), Tourism Enterprises and the Sustainability Agenda across Europe (2012), UK: Ashgate Publishing, pp. 151-168.

Badulescu D., Bungau C., Badulescu A. (2015). Sustainable development through sustainable businesses. An empirical research among master students, Journal of Environmental Protection and Ecology, 16 (3), pp. 1101-1108.

Blancas F., Gonzalez, M., Lozano-Oyola M., Perez F. (2010). The assessment of sustainable tourism: application to Spanish coastal destinations. Ecological indicators, 10, pp. 484-492.

Calidad Turística Española. Instituto para la Calidad Turística Española. (2017). Available online in: www.calidadturistica.es.

Carrillo M., Jorge, J. (2017). Multidimensional Analysis of Regional Tourism Sustainability in Spain, Ecological Economics, 140, pp. 89 - 98.

Dans E., Gonzalez P. (2019). Sustainable tourism and social value at World Heritage Sites: Towards a conservation plan for Altamira, Spain. Annals of Tourism Research, 74, pp. 68 80.

Dresner, S. (2008). Principles of Sustainability, London: Earthscan.

Eurostat (2019). Population on 1st January 2019. Available online at https://ec.europa.eu/eurostat/data/database.

Ferran-Aranaz, M. (2001). SPSS para Windows. Análisis estadístico. Madrid: Osborne McGraw-Hill.

García, M. (2013). VI CURSO DE GESTIÓN DE LA CALIDAD. UNA VISIÓN PRÁCTICA. UNIVERSIDAD DE MÁLAGA. UMA. Ponencia Invitada: "Turismo, Calidad y Formación". Málaga.

Hacia, E. (2016). The impact of tourist traffic on the functioning of Polish seaside health resorts, published in 2nd International Conference "Green Cities - Green Logistics for Greener Cities", 2-3 March 2016, Szczecin, Poland.

Kruskal, W. (1952). A nonparametric test for the several sample problems. The Annals of Mathematical Statistics, 23 (4), pp. 525-540

Lundeberg, E. (2017) The importance of tourism impacts for different local resident groups: A case study of a Swedish seaside destination, Journal of Destination Management, 6, pp.46-55. 
Statista. El portal de estadísticas. Turismo y hostelería. Viajes de ocio. Número de playas certificadas con la $Q$ de calidad Turística en España en 2017. Available online in: https://es.statista.com/estadisticas/554427/playas-certificadas-con-la-q-de-calidad-

turistica-por-comunidad-autonoma-en-espana/

Statistics National Institute (INE) (2017). Encuesta de turismo. Available online in: www.ine.es

Sverdrup, H. and Svensson, G.E. (2002). Defining sustainability, in Sverdrup. H. and Stjernquist, I. (Eds.) Developing principles and models for sustainable forestry in Sweden, (eds), Springer Science, Dordrecht, pp. 21-32.

Sidney, S. and Castellan, J. (1988). Nonparametric Statistics for the Behavioral Sciences. McGraw-Hill Publishing Co. 2nd edition;

UNWTO (2019). International tourism highlights, available at https://www.eunwto.org/doi/pdf/10.18111/9789284421152

World Tourism Organization (OMT). (2015). El turismo más de cerca: medición y análisis subnacional - hacia un conjunto de orientaciones de la OMT.

\section{Bio-notes}

Raquel García Revilla is an Adjunct Professor in the Degree of Companies and Tourist Activities, Adjunct Professor in the Degree of Marketing, Coordinator of the Master's Degree in Hotel Management, Coordinator of the Master's Degree at Madrid Open University, UDIMA (Spain). Her main areas of expertise are Accommodation Management, New Technologies Applied to Tourism, Human Resource Management, Hotel Accessibility, Tourism Sustainability.

Olga Martínez Moure is an adjunct Professor in the Degrees of Business and Tourist Activities, Labor Sciences and Human Resources, and Humanities and in the Master's Degree in Hotel Management at Madrid Open University, UDIMA (Spain). Her main areas of expertise are Socio-health programs applied to the elderly, Health tourism, Employment policies, Social economy.

Bac Dorin Paul is an Associate Professor and the Head of the Department of Economics and Business of the University of Oradea (Romania). His main areas of expertise are tourism, sustainable development, ecotourism and sustainable tourism. 